\title{
SOBRE OS BASTIDORES DO PROCESSO DE FORMULAÇÃO DE POLÍTICAS PÚBLICAS: considerações acerca da saúde bucal no Brasil
}

\author{
Danielle do Valle Garcia \\ Ministério da Saúde
}

SOBRE OS BASTIDORES DO PROCESSO DE FORMULAÇÃO DE POLÍTICAS PÚBLICAS: considerações acerca da saúde bucal no Brasil

Resumo: Este trabalho trata do processo de formulação de políticas específicas, no contexto da política de saúde. Busca compreender o processo de construção da Política Nacional de Saúde Bucal no período de 2000 a 2004, visando identificar os elementos que possam ter contribuído no processo. O estudo possibilitou comparar dois processos de formulação de políticas distintos, a saber: a entrada da saúde bucal no PSF e a Política Nacional de Saúde Bucal Brasil Sorridente. No primeiro momento, a política foi forjada aproveitando as janelas de oportunidades abertas pela ênfase na atenção básica e na adoção do PSF nas instâncias superiores. No segundo momento, ao contrário, um grupo com forte matiz político-partidário formulou um projeto político para a saúde bucal, ainda fora do espaço institucional do governo. Uma vez ocupado esse espaço, o que envolveu uma articulação direta com a Presidência da República, deu-se a forma da Política nacional de Saúde Bucal.

Palavras-chave: Políticas públicas, políticas de saúde, saúde bucal.

THE BACKSTAGE OF THE FORMULATION PROCESS OF PUBLIC POLICIES: considerations about oral health in brazil Abstract: This work is about the process of specific policies formulation, on the context of the politics health. It searches to understand the construction process of National Politics of Oral Health on the period from 2000 to 2004, aiming to identify elements that may have contributed on the process. The study allowed to compare two distinct processes of policies formulation to know: The entry of oral health on PSF and the National Politics of Oral Health "Brasil Sorridente". On a first moment, the policy has been forged taking advantage of the open opportunities by the emphasis on basic attention and adoption of PSF on superior instances. On a second moment, on the contrary, a strong partisan political group formulated a politic project for oral health, still out of govern institutional space. This space once occupied which involved a direct articulation with the Presidency of the Republic, which developed for the National Politics of Oral Health. Key words: Public policies, health policies, oral health. 


\section{INTRODUÇÃO}

A revisão da literatura aponta que diferentes autores vêm trabalhando questões no campo da análise histórica dos serviços odontológicos prestados no Brasil (CÓRDON, 1998; CUNHA, 1952; MOREIRA, 1999). Alguns estudam os diferentes conceitos de Odontologia em Saúde Coletiva e os caminhos percorridos para a consolidação da profissão (BOTAZZO,1992; CHAVES, 1977). Outros avaliam a inclusão da saúde bucal em programas específicos, como no Programa Saúde da Família - PSF (ZANETTI, 2001; CALADO, 2002). Contudo, percebemos um vazio de produção que analisasse 0 processo no qual a saúde bucal vem-se constituindo enquanto política e que desse conta de responder, pelo menos em parte, a nossas inquietações sobre o processo de formulação.

Propomos compreender o processo de construção da Política Nacional de Saúde Bucal no contexto da política do SUS. Escolhemos olhar a política através do ator institucional específico - o Ministério da Saúde, pois o Executivo Saúde no Governo federal desempenha um papel extremamente relevante na formulação da política de saúde e na política de saúde bucal. Neste sentido, olhar a formulação da política desde o ângulo desse ator institucional pode ser uma primeira aproximação para identificar os elementos que possam ter contribuído no processo, buscando os outros atores envolvidos, quais as principais ações e estratégias desenvolvidas por eles e seus desdobramentos na formulação da política.

Tendo em vista a pequena bibliografia sobre a política de saúde bucal na perspectiva que adotamos, vale ressaltar que este trabalho não trata de um estudo aprofundado, mas pode-se dizer que, na prática, a presente investigação assumiu um caráter exploratório sobre o assunto.

O desenho metodológico deste estudo incluiu três etapas. A primeira consistiu na identificação dos documentos publicados pelo Ministério da Saúde. Esses documentos foram coletados através do site do MS e de informantes privilegiados.

De imediato, três marcos chamaram a atenção na primeira visualização: a entrada da saúde bucal no PSF, as Diretrizes da Política Nacional de Saúde Bucal e o Programa Brasil Sorridente. Em função disto, decidimos que o período de análise iria centrar o período pós-SUS, abrangendo os três momentos, que na hipótese da pesquisa eram tidos como um processo contínuo. Ou seja, o nosso pressuposto inicial era de que a política tivesse sido construída num processo linear. Numa tentativa de aproximação por datas, considerávamos a que a "fecundação" da política teria acontecido no ano de 2000, com a iniciativa de inserção das equipes de saúde bucal no PSF. O "embrião", no início do ano 2004, com a publicação das Diretrizes da Política Nacional de Saúde Bucal e o "nascimento", no segundo semestre de 2004, com a criação do Programa Brasil Sorridente. Vale sinalizar, que o referido período abarcou parte do governo Fernando Henrique Cardoso, parte do governo Lula e contou com três coordenações nacionais de saúde bucal.

Numa segunda etapa, realizamos análise dos documentos oficiais e, posteriormente, elaboramos um processo de entrevistas semiestruturadas com os protagonistas do processo. Entrevistamos os coordenadores nacionais da área de saúde bucal que ocuparam o cargo no período de 2000 a 2004. A escolha por entrevistar os coordenadores foi feita porque eles foram atores efetivamente presentes e capazes de resgatar a memória do processo político de formulação. A entrevista tinha, portanto, o objetivo de elucidar algumas características quase dos bastidores da política.

No plano da análise, buscamos aprofundar algumas das questões dos atores ou dos documentos, na medida em que apareceram no relato dos coordenadores.

Desta forma, o presente trabalho não tem a pretensão de oferecer uma narrativa ampla do processo de formulação. Limitamo-nos, por uma questão do recorte escolhido, àquilo que foi evocado por protagonistas dessa formulação de políticas desde o MS.

No desenvolvimento do estudo, foi possível delimitar dois momentos bastante distintos no processo de formulação das políticas de saúde: a inserção da saúde bucal no Programa Saúde da Família e a construção da Política Nacional de Saúde Bucal. A partir daí, identificamos três marcos na trajetória da política de saúde bucal.

O primeiro marco foi a edição da portaria $\mathrm{GM} /$ MS n. ${ }^{\circ} 1.444$, de 28 de dezembro de 2000 (BRASIL, 2000), que estabeleceu as formas de inserção das equipes de saúde bucal no Programa Saúde da Família (PSF). O segundo marco foi a publicação das Diretrizes da Política Nacional de Saúde Bucal, em janeiro de 2004 (BRASIL, 2004b), que apontou caminhos para reorganização da saúde bucal em todos os níveis de atenção. E o terceiro foi a construção do Programa Brasil Sorridente (BRASIL, 2005), também em 2004, que efetivou a saúde bucal enquanto uma política pública de âmbito nacional. Os marcos citados formam a espinha dorsal de nossa investigação.

\section{A SAÚDE BUCAL NA AGENDA DA ATENÇÃO BÁSICA}

A portaria GM n. ${ }^{0} 1.444 / 2000$ estipulou os incentivos financeiros para as equipes de saúde bucal no Programa Saúde da Família (PSF). Contudo, o Programa Saúde da Família já estava sendo implantado há sete anos, e a decisão de torná-lo um modelo substitutivo já havia sido tomada, com a criação dos incentivos para a ampliação da cobertura do programa. Para compreendermos o 
processo de elaboração da portaria retomamos o ano de 1995, momento da entrada de uma nova coordenadora na Área Técnica de Saúde Bucal na Secretaria de Políticas de Saúde (SPS) do Ministério da Saúde. Trata-se de uma profissional com experiência nos serviços assistenciais de saúde bucal em cidade do interior, que havia chegado a Brasília por motivos particulares. Essa experiência parece ter sido importante para sua indicação para o cargo de coordenador, que se encontrava vago.

Uma das primeiras ações desenvolvidas pela coordenação foi um levantamento epidemiológico nas capitais brasileiras, para mapear a situação de saúde bucal da população.

De acordo com a entrevistada, o interesse para o PSF surgiu das leituras que faziam sobre o programa que estava em plena expansão no país desde a sua criação, em 1994, e em resposta a um "incômodo" gerado pelo fato dos odontólogos não estarem inseridos na equipe. A saúde bucal não possuía, até então, orçamento próprio, o que para o corpo técnico que assumiu era uma questão relevante. O amadurecimento da possibilidade de entrada da saúde bucal no PSF, prioridade para a Secretaria de Políticas de Saúde, impulsionou a busca por ampliação de recursos durante todo o ano de 1998 e 1999. Esse processo foi denominado pela coordenadora de "período de arrumar a casa".

No relato da coordenadora, encontramos pistas de uma certa configuração de como o problema estava sendo formulado, o que Kingdom (1995) chama de "stream do problema". A coordenação de saúde bucal não possuía a formulação de um projeto prévio claro. O silêncio na fala da coordenação sobre os modelos de assistência indica que não havia o objetivo de organizar propriamente um modelo de assistência que desse conta dos problemas de saúde bucal da população, que inclusive tinham sido levantados no diagnóstico realizado em 1996. Desta forma, a formulação do problema estava baseado na criação de algo que pudesse superar uma diferença: a organização de um espaço institucional.

Como não possuía alta centralidade, a inserção das equipes de saúde bucal no PSF não foi prevista no Plano Plurianual. Portanto, precisou ser um processo negociado entre a coordenação e o secretário de Políticas de Saúde. Segundo a entrevistada, todo o processo de elaboração teve a participação da equipe composta por cinco técnicos e pelos integrantes do comitê de assessoramento que contribuíram no desenho de diversos cenários até se chegar a uma proposta satisfatória dentro dos limites financeiros estipulados pelo secretário de Políticas de Saúde.

Após a definição dos valores a serem repassados, partiu-se para a elaboração das normas para solicitação dos incentivos para as equipes de odontologia no PSF. Segundo essas normas, para receber os incentivos, a habilitação do município deveria ser aprovada pela Comissão Intergestores
Bipartite $(\mathrm{CIB})$ que remetia à Secretaria de Políticas de Saúde a relação dos municípios qualificados, seguindo a mesma lógica do PSF.

A coordenadora relatou ter apresentado a proposta para alguns atores, por sua própria iniciativa, numa tentativa de garantir a adesão da classe odontológica, mas até então, não havia participação das entidades odontológicas no processo.

É interessante notar que o desenho da equipe de saúde bucal e dos modos de sua operação não estavam pré-definidos, mas foram sendo elaborados no bojo das negociações por recursos. É possível reconstruir as opções estratégicas. Existiam duas opções: estabelecer os incentivos de acordo com - limite orçamentário definido pela Secretaria de Políticas de Saúde, mesmo que ele acarretasse um número de pessoas inadequadamente grande para cada equipe de saúde bucal, ou se adiaria a criação dos incentivos até a obtenção de recursos suficientes. Assumiu-se a primeira opção com a expectativa de conseguir mais recursos posteriormente.

Lançada a portaria "financeira", foi elaborado - Plano de Reorganização das Ações de Saúde Bucal na Atenção Básica, integrado à portaria $n .^{\circ}$ 267/01, de 6 de março de 2001 (BRASIL, 2001), que estabeleceu aquilo que poderia ser chamado de "a regra do jogo".

Note-se que o Plano de Reorganização das Ações de Saúde Bucal é posterior ao desenho dos esquemas básicos de funcionamento das equipes e dos dispositivos de repasse de recursos através dos incentivos. Ou seja, o conteúdo do projeto foi elaborado após a construção de sua viabilidade.

$\mathrm{Na}$ visão da coordenação, esse documento era necessário, pois se tratava de uma "política nova" dentro de uma estrutura que já existia (o PSF), ofertada a uma categoria que historicamente organizava seu processo de trabalho num espaço fechado e isolado, que é o consultório. A nova proposta demandava um novo modo de atuação profissional, abrangendo diferentes conhecimentos,

[...] dentro da filosofia do saúde da família, que trabalhava com a universalidade, equidade, integralidade, enquanto a odontologia trabalhava dentro de um consultório, sem participar de planejamento, de ações de adscrição de clientela." (BRASIL, 2001).

Abril de 2001 foi o mês que, segundo a coordenadora, de fato começou o processo de habilitação dos municípios. Nesse período se afirmou o que a coordenação receava ocorrer. Foram encontradas dificuldades na implantação de equipes de modalidade 2 (composta por Odontólogo, Técnico de Higiene Dental e Auxiliar de Consultório Dentário), pois não existiam profissionais qualificados na área técnica. Outras dificuldades surgiram no momento da implantação, como a alta rotatividade de cirurgiões- 
dentistas e a exigência de curso de formação para os auxiliares de consultório dentário (ACD) por parte do Conselho Federal de Odontologia (CFO).

As dificuldades apontadas pela coordenadora são, em grande parte, reflexo da situação na qual se encontrava a área de saúde bucal. O número de técnicos era pequeno, não existia orçamento próprio, o cargo de coordenador da Área Técnica estava desocupado no momento em que ela assumiu. Esses fatores são indicadores de uma baixa centralidade na agenda.

Desta forma, a entrada da saúde bucal no PSF representou o aumento da centralidade na agenda da atenção básica, na medida em que ela colou em problemas centrais da agenda do Executivo da Saúde (BAPTISTA, 2003) por um processo de subordinação, ou seja, a saúde bucal se encaixou no PSF através de uma janela de oportunidades. Por outro lado, a entrada na agenda não garantiu a centralidade para a saúde bucal, pois todos os arranjos institucionais utilizados são os mesmos do PSF, e nestes arranjos há uma prioridade menor para saúde bucal do que para os outros.

Apesar de a coordenação acreditar que tudo era novo, quando olhamos para os dispositivos institucionais, encontramos os mesmos que já eram utilizados na política maior de descentralização: a habilitação dos municípios e a normatização via portarias. Nãohouve, pois, inovaçãonos instrumentos adotados pela política. O PSF caracterizou-se por ser uma política elaborada para incentivar os municípios a implantá-la através de um dispositivo financeiro que aumenta conforme a ampliação da cobertura. No caso da saúde bucal, esse dispositivo não esteve presente, uma vez que os incentivos não são alterados conforme a ampliação da cobertura. É possível considerar que a aposta do Executivo Saúde no crescimento da saúde bucal foi feita em menor escala do que para o PSF.

Por sua vez, na análise desse processo, não se identificou um cenário de disputa com atores externos, mas sim, uma negociação a partir de um nicho de oportunidade, e neste caso, a coordenação assumiu a postura de mediadora entre a oportunidade apresentada e o movimento da categoria.

\section{A POLÍTICA NACIONAL DE SAÚDE BUCAL BRASIL SORRIDENTE}

Poderíamos pensar que a proposta do Brasil Sorridente decorreu naturalmente dos desenvolvimentos institucionais da política de entrada da saúde bucal no PSF. Entretanto, neste estudo não conseguimos encontrar com clareza elementos de continuidade entre estas duas políticas no plano institucional. Ao contrário, encontramos discursos e falas que ressaltavam o hiato existente entre as políticas. Isto não implica, necessariamente, descontinuidade do debate que vinha sendo feito por atores externos ao Ministério da Saúde.
Durante entrevista com o coordenador de saúde bucal da gestão Lula, identificamos que, aparentemente, parte desse debate se aglutinou em torno dos grupos que participaram da construção do programa do governo. De fato, o processo desta candidatura contou com a articulação de trabalhadores da área odontológica e demais profissionais de saúde, alguns com experiências em prefeituras do Partido dos Trabalhadores (PT) e outros vindos diretamente do debate acadêmico e que se incumbiram da elaboração do programa de governo. Portanto, foi através da mobilização de um partido político que se organizou o projeto apresentado na instituição.

Com a vitória do presidente, esse grupo articulado se colocou para detalhar as linhas de ação do Executivo na área da saúde bucal. Foi realizada uma série de reuniões com os partidos da base de sustentação (PT, PSB e o PC do B). Conforme relatado em entrevista, um dos encontros realizado em São Paulo reuniu cerca de 100 pessoas de diferentes áreas de formação com alguma discussão na saúde bucal e que participaram da plenária, lançando as bases para o trabalho que seria desenvolvido. A síntese do encontro ficou registrada num documento chamado Fome Zero e Boca Cheia de Dentes (BRASIL, 2002), proposta para a saúde bucal no governo Lula, dirigida à equipe de transição.

Chama a atenção nesse documento a tentativa quase caricatural, já indicada no título, de estabelecer a relação entre a proposta saúde bucal ao Programa Fome Zero, que parecia ser o programa prioritário do governo recém-eleito. Busca dessa forma, angariar o apoio direto do futuro presidente, mais do que articular-se no conjunto da proposta para o SUS. No mesmo sentido, o documento apresenta as propostas de ações a serem desenvolvidas na saúde bucal, bem como identifica o perfil considerado adequado para conduzir a política de saúde bucal no novo governo. Trata-se, pois, de um documento feito no contexto da disputa política de um grupo pelo espaço institucional no qual se faria a formulação da política de saúde bucal.

O documento mostra a existência de uma articulação de profissionais de saúde e de saúde bucal no âmbito do PT (e de sua base aliada), com um projeto político que situava a saúde bucal no conjunto de uma perspectiva da saúde, dentro de um conjunto de uma perspectiva mais geral. $\mathrm{E}$ que pautava como elemento central não apenas a definição de propostas específicas, como a sugestão de nomes para os cargos e a proposta de uma maior visibilidade para a política. Essa articulação é confirmada também pela fala do coordenador, durante a entrevista.

A demanda desse grupo foi atendida. Logo após a posse do presidente Lula foi feita uma série de alterações de estrutura no interior do Ministério da Saúde. No bojo dessas mudanças foi pactuada a transformação da Área Técnica de Saúde Bucal 
para Coordenação Nacional de Saúde Bucal, que permaneceu na hierarquia institucional subordinada ao Departamento de Atenção Básica, que por sua vez está subordinado à Secretaria de Atenção à Saúde.

Esta mudança de nomenclatura parece ter para o coordenador grande importância, na medida em que, em sua fala, pontua essa alteração como a primeira negociação feita com o ministro. Por sua vez, podemos observar que a agenda da saúde bucal proposta, é muito mais ampla do que a agenda da atenção básica, à qual ela estaria subordinada. Há evidências na própria fala do coordenador que mostram um alcance e um poder de relação maior que não é restrito a essa aparente institucionalização. Ou seja, a subordinação no organograma, neste caso, não reflete a inserção real. Em outros termos, ao virar coordenação, a saúde bucal não foi "aprisionada" num órgão da estrutura administrativoburocrática do Ministério da Saúde.

A produção normativa da nova Coordenação cresceu muito durante o ano de 2003 e início de 2004. Os primeiros esforços, contudo, foram no sentido de reforçar as iniciativas implantadas nas gestões anteriores: os valores dos incentivos financeiros para as ações de saúde bucal no âmbito do PSF foram reajustados pela primeira vez desde o ano 2000, e as regras que delimitavam o número de equipes de saúde bucal foram flexibilizadas. Por sua vez, alguns novos elementos foram introduzidos na atenção básica em odontologia, como o procedimento de moldagem, adaptação e acompanhamento para prótese, indicando um enriquecimento desse nível de atenção, coerente com os princípios constitucionais do SUS.

No processo da formulação da política, mais importante do que esses passos foi a publicação, em janeiro de 2004, das Diretrizes da Política Nacional de Saúde Bucal.

Uma análise desse documento mostra que ele é bastante coerente com as propostas anteriormente apresentadas para a saúde bucal no documento Fome Zero e Boca Cheia de Dentes, o que indica que o grupo, uma vez tendo assumido a coordenação, buscou implementar as propostas que vinha defendendo. Mas, em certo sentido, o texto das Diretrizes utiliza conceitos que inovam ou que vão além do que foi apresentado no documento para a equipe de transição, que são: o cuidado, a integralidade a gestão participativa. O uso dos termos "humanização" e "cidadania" caracterizam o processo pelo qual se constituíram os princípios. Entre as ações definidas pelas Diretrizes, algumas se apresentam como inovações, pois incluem nas rotinas de assistência métodos que aprimorem os serviços e garantam a atenção, de fato, do indivíduo em todas as suas necessidades, nas esferas da atenção básica, secundária e terciária.

Para a atenção básica, em especial, ficou designada a competência para assumir a responsabilidade pela detecção das necessidades, providenciar os encaminhamentos requeridos em cada caso e monitorar a evolução da reabilitação, bem como acompanhar e manter a reabilitação no período pós-tratamento.

Também foi prevista a inserção de procedimentos mais complexos. Para a média e alta complexidade o documento faz críticas ao modo como a assistência odontológica tem-se restringido quase que exclusivamente aos serviços básicos no país, tendo os procedimentos especializados um percentual baixíssimo do total dos procedimentos odontológicos, o que compromete o desenvolvimento do sistema de referência e contrarreferência. Sinaliza a necessidade de investimentos que permitam aumentar 0 acesso aos níveis mais complexos do sistema e para atender a esse desafio institui os Centros de Referência de Especialidades Odontológicas (CREO), que mais tarde, junto com o procedimento de prótese inserido na atenção básica, seriam o grande carro-chefe da divulgação do Brasil Sorridente.

A partir do texto Fome Zero e Boca Cheia de Dentes, estabeleceu-se que a saúde bucal demandava uma política efetiva, "sendo muito mais abrangente do que aprisionar a saúde bucal num órgão da estrutura administrativo-burocrática do Ministério da Saúde".

Neste sentido, as Diretrizes apresentam a tal Política Nacional de Saúde Bucal, evocada pelo documento-base construído durante o período de transição, operacionalizando grande parte das ações balizadas anteriormente e detalhando a discussão a partir de alguns conceitos que aparecem pela primeira vez no bojo da saúde bucal.

Portanto, a Política Nacional de Saúde Bucal estruturou-se em cima de certos valores do SUS. Antes disso, ela responde a certos valores da sociedade brasileira, pois estes estão na Constituição Federal de 1988.

O nexo com o SUS e seus princípios, conforme explicitado, decorreu desde o grupo da coligação. Entretanto, também desde lá existiu uma outra trajetória na linha do marketing político que se ancorou na expressão "fome zero e boca cheia de dentes" e na articulação com a agenda prioritária do Executivo Presidência, que naquele momento inicial estava centrada na estratégia de luta para entrar no governo. Este modelo segue sendo valorizado, no discurso do Presidente da República durante o lançamento da Política Nacional em Sobral (BRASIL, 2004a) e na contínua evocação do coordenador da centralidade para o Executivo Presidência e na marca dada ao Brasil Sorridente.

A saúde bucal começou a ocupar, então, lugar de destaque nos veículos de divulgação do governo. A logomarca Brasil Sorridente espelhava a alegria em sorrir na perspectiva do direito. Vendeu com sucesso a proposta da política que visa a ampliar o acesso e melhorar as condições de saúde bucal 
da população brasileira, tornando-se "a menina dos olhos", pois se configurou como a primeira política efetiva de governo na área de saúde bucal dentro do SUS.

Foram encontrados, durante a entrevista, elementos na fala do coordenador que demonstram a centralidade que a saúde bucal passou a ter na agenda do Executivo Presidência: o acesso a reuniões com o presidente Lula e a cobrança sistemática deste em relação aos resultados da política, a manutenção do coordenador no cargo após a mudança de ministro, o aumento gradativo dos recursos para o área. Este crescimento da centralidade é visível, inclusive, na ampliação do espaço físico de ocupação e da equipe técnica que integra a Coordenação Nacional de Saúde Bucal.

A política foi ancorada fortemente nos valores do SUS. Porém, cabe notar que ao se apresentar a política para a sociedade, foi dada uma ênfase maior no marketing político do que da conexão dos princípios da saúde bucal com os princípios da saúde como direito. É como se o Brasil Sorridente surgisse como um programa autônomo, característico do governo do PT.

O estudo mostra que as bases técnicas da formulação foram feitas por uma base organizada pelo grupo do $\mathrm{PT}$ ligado à discussão das diretrizes do SUS, que formulou uma demanda. Ao fazer esta demanda, o grupo também gerou uma demanda de marketing quando fez a associação com o Programa Fome Zero. Associação que, de fato, nunca foi inerente à política de saúde bucal. Do ponto de vista do discurso, houve uma ênfase maior dos nexos do Brasil Sorridente com o Fome Zero e com as prioridades apresentadas pelo Executivo Presidência do que dos nexos com o SUS, apesar da consistência da proposta expressa no documento da política nacional ser diretamente conectada aos valores do SUS.

\section{CONCLUSÃO}

Ao longo do nosso estudo, identificamos dois importantes momentos de tentativa de crescimento da centralidade da saúde bucal na agenda geral da saúde no Ministério da Saúde, que foram: a entrada da saúde bucal no PSF e a Política Nacional de Saúde Bucal Brasil Sorridente. Nos dois momentos houve tentativas articuladas de aumento da centralidade da saúde bucal na agenda. No primeiro momento, a tentativa ocorreu através da busca do espaço institucional e de recursos financeiros, que só avançou na medida em que precisou negociar com os níveis superiores do Ministério da Saúde. Essa empreitada parece ter partido de uma trajetória intratécnica dentro de um nicho institucional fragilmente colocado e não central à política. Esteve conectada ao Executivo Saúde, onde se construiu uma proposta de entrada no PSF, através de uma janela de oportunidades, o que permitiu uma articulação subordinada à política de atenção básica. Neste caso, foi a figura do burocrata que esteve presente no movimento para a construção da proposta, que lutou internamente por isso, que definiu determinadas questões e negociou com atores externos. Vale lembrar, que os atores externos que aparecem na fala da gestora e nos documentos oficiais não fizeram reivindicações; na verdade, os atores externos só participaram do posicionamento, inclusive com tensões, sobre a proposta levada pela coordenação. Acreditamos que, apesar da ausência de demanda externa significativa, de projeto previamente articulado e de articulações institucionais relevantes, a coordenação da Área Técnica de Saúde Bucal naquele primeiro momento gerou uma entrada significativa da saúde bucal na agenda do PSF. O que nos chamou a atenção nesse processo foi a busca de espaço institucional e a inexistência de um projeto previamente articulado para a saúde bucal.

Já no segundo momento, encontramos um ator que possuía um projeto político que disputou o espaço institucional para a sua implementação, lutando pela sua legitimidade e centralidade.

Neste caso, o que nos chamou a atenção foi a relação inversa àquela estabelecida na gestão anterior, pois na trajetória percorrida, a janela de oportunidade foi dada por um processo de uma nova coalizão do governo que permitiu que o projeto da saúde bucal pudesse se apresentar concretamente como proposta de articulação e permitiu, ainda, a geração das consequências institucionais.

Observamos que a característica da Política Nacional de Saúde Bucal possui uma base técnica de conexão com o SUS e com o Marketing político. O esforço em fazer um elo entre a política com determinados pontos do marketing considerados centrais na agenda do Executivo Presidência esteve presente desde o início da proposta. Talvez, este caminho reflita a trajetória da macropolítica no Brasil que adotou a relação da dinâmica entre o marketing político e a dinâmica da formulação de políticas.

Existem, neste sentido, evidências de que talvez o caso da formulação de políticas de saúde bucal durante o governo Lula possa ser um caso ilustrativo de uma política de base técnica seduzida pelo marketing político. Encontramos neste programa elementos de uma forma de atuar da política no jogo democrático que sugerem uma captura do político pelo marketing.

Isto nos permite dizer que a estratégia do marketing político utilizada destacou a saúde bucal do conjunto das questões, mas ao mesmo tempo, poderá gerar problemas de sustentabilidade da Política Nacional de Saúde Bucal nos governos posteriores.

Em nosso estudo não encontramos evidências da participação significativa, em ambos os momentos de formulação, de atores externos envolvidos no processo. Localizamos a questão a partir do ponto de vista do Executivo Saúde. No processo de entrada da saúde bucal no PSF, o ator relevante foi a burocracia constituída pelo grupo que estava no Executivo Saúde fazendo leituras técnicas a partir daquele espaço 
e pautando as articulações e as negociações. No processo de formulação da Política Nacional de Saúde Bucal Brasil Sorridente, o ponto central dizia respeito ao processo que antecedeu a entrada do coordenador e que, inclusive, garantiu sua entrada no governo. Ou seja, a organização de um grupo de profissionais da saúde e da saúde bucal que vinham atuando no PT, que tinham compromisso com o movimento sanitário e uma leitura partidária do projeto de sociedade. Vale ressaltar que neste momento o coordenador assumiu o cargo justamente por representar o movimento que o indicou e que, portanto, organizou um espaço de poder completamente diferente do que havia na gestão anterior. Desta forma, existiram atores presentes no processo, mas a condução do processo de formulação foi toda do Executivo Saúde nos dois momentos.

Podemos dizer, portanto, que ambas as gestões avançaram. Não se trata de um avanço contínuo, uma vez que ele ocorreu desde condições distintas. Essas condições distintas englobaram a própria trajetória dos atores sociais.

Identificamos que o poder no espaço institucional cresceu e está crescendo, mas trata-se de um poder profundamente diferenciado. Ele não foi derivado do crescimento institucional, mas derivou das características específicas dos dois processos de formulação da política.

\section{REFERÊNCIAS}

BAPTISTA, T. W. F. Políticas de saúde no pósconstituinte: um estudo da política implementada a partir da produção normativa dos poderes executivo e legislativo no Brasil. 2003. 369 f. Tese (Doutorado em Saúde Coletiva) - Instituto de Medicina Social, Universidade do Estado do Rio de Janeiro, Rio de Janeiro, 2003.

BOTAZZO, C. Saúde Bucal Coletiva: um conceito em permanente construção. São Paulo, 1992.

BRASIL. Ministério da Saúde. Assessoria de Comunicação Social. Saúde Bucal - Sobral/CE. Brasília, DF, 17 mar. 2004a. Discurso do Presidente da República (transcrição). Disponível em:<http:// dtr2004.saude.gov.br/dab/saudebucal/brasil_ sorridente.php>. Acesso em: 10 fev. 2006.

Brasil Sorridente. Brasília, DF, 2005. Disponível

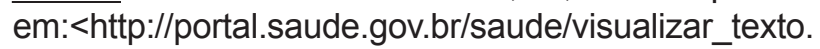
cfm?idtxt=19578>. Acesso em: 16 jun. 2005.

Diretrizes da Política Nacional de Saúde Bucal. Brasília, DF, 2004b.

BRASIL. Ministério da Saúde. Fome Zero e boca cheia de dentes. Brasília, DF, 2002. 8 p. Mimeo.
Portaria n. ${ }^{\circ} 1.444$, de 28 de dezembro de 2000. Incentivos à saúde bucal no PSF. Brasília, DF, 2000.

Portaria n. ${ }^{\circ}$ 267, de 06 de março de 2001. Incentivo a saúde bucal no PSF. Brasília, DF, 2001.

CALADO, G. S. A inserção da equipe de saúde bucal no Programa Saúde da Família: principais avanços e desafios. 2002. Dissertação (Mestrado em Saúde Pública) - Escola Nacional de Saúde Pública, FIOCRUZ, Rio de janeiro, 2002.

CHAVES, M. M. Odontologia social. 2 ed. Rio de Janeiro: Labor do Brasil, 1977.

CORDÓN, J. A construção de uma agenda para a saúde bucal coletiva. Revista Ação Coletiva, Brasília, DF, v.1, n.1, 1998.

CUNHA, E. S. História da odontologia no Brasil: 1500-1900. 2. ed. Rio de Janeiro: Científica, 1952.

KINGDOM, J. Agendas, alternatives and public policies. 2. ed. [S.I.]: Harper Collins College Publis, 1995.

LEMIEUX, V. Les Politiques publiques et les alliances d'acteurs. In: LEMIEUX, V. et al (Org.). Le système de santé au Quebec: organisation, acteurs at enjeux. Saint-Foy: Les Press de L'Université Laval, 1994.

MOREIRA, L. C. H. A saúde bucal coletiva no contexto do Programa Médico de Família de Niterói - RJ: o dentista de família. 1999. 148 f. Dissertação (Mestrado em Odontologia Social) Universidade Federal Fluminense, Niterói,1999.

ZANETTI, C. H. G. As marcas do mal-estar social no Sistema Nacional de Saúde: o caso das políticas de saúde bucal, no Brasil dos anos 80 . 1993. Dissertação (Mestrado em Saúde Pública) - Escola Nacional de Saúde Pública, Fundação Oswaldo Cruz, Rio de Janeiro, 1993.

\section{Danielle do Valle Garcia}

Assistente Social

Doutoranda em Política Social pela Universidade Federal Fluminense

Assistente Social do Ministério da Saúde

E-mail: danielledovalle@yahoo.com.br

\section{Ministério da Saúde}

Esplanada dos Ministérios Bloco G, Brasília-DF CEP: $70058-900$ 